\title{
Treatment of chronic intractable neuropathic pain with dronabinol: Case report of two adolescents
}

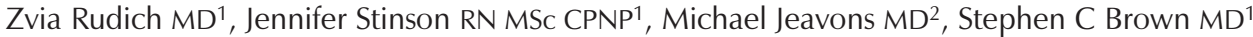

Z Rudich, J Stinson, M Jeavons, SC Brown. Treatment of chronic intractable neuropathic pain with dronabinol: Case report of two adolescents. Pain Res Manage 2003;8(4):221-224.

OBJECTIVE: To evaluate the effectiveness of dronabinol for the treatment of neuropathic pain refractory to previous treatment. METHODS: We studied the response (reduction of pain intensity and functional improvement) to dronabinol ( $5 \mathrm{mg} /$ day to $25 \mathrm{mg} /$ day) in two adolescents with neuropathic pain and depression refractory to previous treatments over two and five years, respectively.

RESULTS: Reduction in pain intensity (45\%) was achieved in patient 2 and was unchanged in patient 1 . Functional improvement was markedly increased in terms of academic performance, mood and sleep in both patients over four to five months, without major adverse effects. While these improvements dissipated over time, the patients were more reconnected with rehabilitation and focused less on the intrusiveness of their pain problem in their every day lives.

CONCLUSIONS: Dronabinol appeared to be effective in improving pain affect and psychosocial functioning in the treatment of refractory neuropathic pain and may be considered as an adjuvant medication in the rehabilitation process. Well-controlled placebo studies are required for further evaluation.

Key Words: Adolescents; Dronabinol; Neuropathic pain

$\mathrm{P}$ atients with complex regional pain syndrome (CRPS) type I present with a type of neuropathic pain that is poorly understood. CRPS type I is characterized by burning pain and variable autonomic symptoms (mottling, cyanosis, coldness and swelling) and trophic changes (altered hair and nail growth, and muscle atrophy). Although many are unable to recall any precipitating event leading to the onset of their pain, pediatric patients often present with a history of minor trauma or repeated stress injury. CRPS type I symptoms significantly interfere with quality of life and daily functioning, often with the magnitude of pain and disability being disproportionate to the inciting event $(1,2)$. A multidisciplinary multimodal approach for the treatment of chronic pain has become the standard practice in our clinic and others (3). For example, one trial employing cognitive behavioural therapy by Lee et al (4) with varying numbers of physiotherapy sessions, showed both treatments reduced pain and disability

\section{Le traitement de la douleur neuropathique chronique réfractaire au moyen de dronabinol : Rapport du cas de deux adolescents}

OBJECTIF : Évaluer l'efficacité du dronabinol dans le traitement de la douleur neuropathique réfractaire à des traitements antérieurs.

MÉTHODOLOGIE : Nous avons étudié la réponse (réduction de l'intensité de la douleur et amélioration fonctionnelle) au dronabinol ( $5 \mathrm{mg} / \mathrm{jour}$ à $25 \mathrm{mg} /$ jour) chez deux adolescents présentant une douleur neuropathique et une dépression réfractaires aux traitements antérieurs sur une période de deux et de cinq ans, respectivement.

RÉSULTATS : Une réduction de l'intensité de la douleur (45\%) a été obtenue chez le patient II, mais pas chez le patient I. Une importante amélioration fonctionnelle a été notée en matière de rendement scolaire, d'humeur et de sommeil chez les deux patients, pendant quatre et cinq mois, sans effet néfaste majeur. Bien que ces améliorations ce soient dissipées au fil du temps, les patients étaient plus concentrés sur leur réadaptation, et moins sur l'intrusion de la douleur dans leur vie quotidienne. CONCLUSIONS : Le dronabinol semble efficace pour réduire l'effet de la douleur et améliorer le fonctionnement psychosocial dans le traitement de la douleur neuropathique réfractaire et peut être considéré comme un médicament auxiliaire dans le processus de réadaptation. Des études bien contrôlées contre placebo s’imposent pour pouvoir procéder à une évaluation plus approfondie.

\footnotetext{
${ }^{1}$ Department of Anaesthesia; ${ }^{2}$ Department of Psychiatry, The Hospital for Sick Children, University of Toronto, Toronto, Ontario

Correspondence: Dr S Brown, Department of Anaesthesia, Hospital for Sick Children, 555 University Avenue, Toronto,

Ontario M5G 1X8. Telephone 416-813-7445, fax 416-813-7543, e-mail stephen.brown@sickkids.ca
} 
TABLE 1

Characteristics of two adolescents treated with dronabinol

\begin{tabular}{|c|c|c|c|c|c|c|c|}
\hline Patient & Sex & $\begin{array}{c}\text { Age } \\
\text { (years) }\end{array}$ & $\begin{array}{c}\text { Past } \\
\text { medical history }\end{array}$ & Site & Etiology & $\begin{array}{l}\text { Disease duration } \\
\text { (months) }\end{array}$ & Treatments before dronabinol \\
\hline$\overline{1}$ & $\mathrm{~F}$ & 15 & $\begin{array}{l}\text { Idiopathic } \\
\text { thrombocytopenic } \\
\text { purpura }\end{array}$ & $\begin{array}{l}\text { Right arm and } \\
\text { shoulder }\end{array}$ & Idiopathic & 48 & $\begin{array}{l}\text { Multimodal pain therapy: } \\
\text { Intensive physiotherapy and desensitization } \\
\text { Transcutaneous electrical nerve stimulation } \\
\text { Acupuncture } \\
\text { Massage therapy } \\
\text { Acetaminophen } \\
\text { NSAIDs (ibuprofen, celecoxib, ketorolac) } \\
\text { Opioids (codeine) } \\
\text { Anticonvulsants (carbamazepine, gabapentin, lamotrigine) } \\
\text { Tricyclic antidepressants (amitriptyline, nortriptyline) } \\
\text { Lidoderm patch } \\
\text { Topical capsaicin } \\
\text { Regional analgesia (right axillary nerve block) }\end{array}$ \\
\hline & & & & & & & $\begin{array}{l}\text { Depression: } \\
\text { Trazodone, extended-release venlafaxine, } \\
\text { citalopram, bupropion }\end{array}$ \\
\hline & & & & & & & $\begin{array}{l}\text { Sleep disturbances: } \\
\text { Trazodone, lorazepam, chloral hydrate, melatonin }\end{array}$ \\
\hline 2 & $\mathrm{M}$ & 14 & Metatarsus varus & $\begin{array}{l}\text { Right foot, leg } \\
\text { and groin } \\
\text { Pain on voiding }\end{array}$ & Post surgical & 60 & $\begin{array}{l}\text { Multimodal pain therapy: } \\
\text { Intensive physiotherapy and desensitization } \\
\text { Transcutaneous electrical nerve stimulation } \\
\text { NSAIDs (ibuprofen, celecoxib) } \\
\text { Opioids (acetaminophen with codeine) } \\
\text { Anticonvulsants (gabapentin, lamotrigine) } \\
\text { Tricyclic antidepressants (amitriptyline, nortriptyline) } \\
\text { Topical capsaicin } \\
\text { Regional analgesia (femoral nerve blocks, lumbar } \\
\text { sympathetic block) } \\
\text { Depression: } \\
\text { Extended-release venlafaxine } \\
\text { Sleep disturbances: } \\
\text { Chloral hydrate }\end{array}$ \\
\hline
\end{tabular}

NSAID Nonsteroidal anti-inflammatory drug

in the developing nervous systems of children. However, studies involving several hundred children using cannabinoid treatment for nausea and vomiting during chemotherapy suggest only negligible side effects (9). The aim of our case report was to evaluate the effectiveness of dronabinol in the treatment of CRPS type I in two adolescents refractory to standard therapy, and to determine the frequency of adverse effects. Taking into consideration that these were pediatric patients, dronabinol appeared to be the only acceptable cannabinoid alternative available for our case report study.

\section{PATIENTS AND METHODS}

A diagnosis of CRPS type I was made in both adolescents based on history and physical examination. Diagnostic investigations were normal (ie, laboratory and radiological examinations). Complaints of neuropathic pain were associated with mechanical allodynia, hyperalgesia, diffuse tenderness to palpation, reduced range of motion, secondary hyperalgesia, and symptoms aggravated by physical activity of the affected area. The affected extremities exhibited variable signs of autonomic dysfunction, edema (patient 1) and decreased temperature (patient 2); while neither had documented colour, trophic hair or nail changes. Table 1 outlines the characteristics of the two adolescents that were treated with dronabinol before starting their therapy. The relentless nature of the pain, resistant to conventional multi-modal therapy, resulted in both adolescents being diagnosed and treated for clinical depression. Depressive symptomatology manifested by both patients included changes in mood, poor cognitive functioning (difficulty concentrating) leading to deterioration in school performance, social withdrawal and sleep disturbances. Patient 1 also experienced lack of appetite. The medical therapies used for treatment of clinical depression and sleep disturbances are outlined in Table 1. Both patients received psychiatric treatment, including a combination of relaxation training, cognitive-behavioural therapy, self-hypnosis and individual psychotherapy. These two adolescents were resistant to an aggressive multidisciplinary treatment for both neuropathic pain and depression for a two-year treatment period before starting the dronabinol.

Using a case report design, we studied the response to dronabinol in two adolescents with neuropathic pain and depression refractory to previous standard treatments who were followed by our comprehensive pain program from 1999. Both 
TABLE 2

Self-reported improvement in physical, psychosocial and role functioning four months after commencing dronabinol treatment

\begin{tabular}{|c|c|c|c|c|c|c|c|c|c|}
\hline \multirow[b]{2}{*}{ Patient } & \multicolumn{4}{|c|}{ Physical functioning } & \multicolumn{2}{|c|}{ Psychosocial functioning } & \multicolumn{3}{|c|}{ Role (school performance) } \\
\hline & $\begin{array}{l}\text { Reduction } \\
\text { in pain } \\
\text { intensity }(\%)\end{array}$ & $\begin{array}{l}\text { Improvement in } \\
\text { pain affect }(\%)\end{array}$ & $\begin{array}{r}\text { Improvement } \\
\text { in sleep (\%) }\end{array}$ & $\begin{array}{l}\text { Improvement } \\
\text { in ADL (\%) }\end{array}$ & $\begin{array}{l}\text { Improvement } \\
\text { in mood }(\%)\end{array}$ & $\begin{array}{l}\text { Improvement } \\
\text { in relations with } \\
\text { peers/family }(\%)\end{array}$ & \multicolumn{2}{|c|}{$\begin{array}{c}\text { Number } \\
\text { of school } \\
\text { days missed } \\
(4 \text { month period) }\end{array}$} & $\begin{array}{c}\text { Improvement } \\
\text { in academic } \\
\text { performance } \\
(\%)\end{array}$ \\
\hline$\overline{1}$ & 0 (arm) & 40 & 100 & 75 & 100 & 20 & 38 & 2 & 100 \\
\hline \multirow[t]{2}{*}{2} & 0 (foot/leg/groin) & 60 & 50 & 60 & 75 & 20 & 5 & 0 & 10 \\
\hline & 5 (pain on voiding & & & & & & & & \\
\hline
\end{tabular}

Percentages (\%) reflect maximum improvement. Percentages based on a 0-100 numerical rating scale. ADL Activities of daily living; Rx Therapy

adolescents were treated with dronabinol after obtaining patient and parent consent. Dronabinol dosage was started at $5 \mathrm{mg}$ once daily at bedtime and titrated in $5 \mathrm{mg}$ increments to the desired clinical response or to the point that bothersome side affects were present. The treatment was evaluated on a weekly basis. Outcome measures were evaluated using a numerical rating scale, which ranged from $0 \%$ to $100 \%$ improvement. Patient 1 reached a maximum dose of $20 \mathrm{mg} /$ day $(20 \mathrm{mg}$ at bedtime), while patient 2 was titrated up to $25 \mathrm{mg} /$ day $(10 \mathrm{mg}$ in the morning and $15 \mathrm{mg}$ at bedtime). The treatment was considered to be effective if the pain was reduced by $30 \%$ and there was reported improvements in physical and psychosocial functioning. During periods of dosage adjustment, both adolescents refrained from driving a car.

\section{RESULTS}

While patient 2 reported no change in the intensity of neuropathic pain, he reported a $45 \%$ reduction in the intensity of pain during voiding. However, both patients noticed a reduction in the affective component of their pain, in that it seemed to bother them less. Despite the lack of reduction in the intensity of pain experienced, a marked improvement in physical (sleep, activities of daily living), psychosocial (mood, peer and family relations) and role (school performance) functioning was evident in both adolescents (Table 2). Four months following the start of treatment, no appreciable reductions were noted in self-reported pain intensity in the affected extremities. Subsequently, antidepressant therapy was discontinued at the request of both patients, followed by complete withdrawal of all analgesic medication. Long term follow-up at six, 10 and 12 months revealed a gradual decline in the improvements noted in physical, psychosocial and role functioning that were noted at the four-month follow-up. Subsequently, both patients asked to stop the treatment because of the gradual dissipation in effectiveness. Side effects of dronabinol included increased appetite, morning sleepiness, lightheadedness and dysphoria, all of which subsided by employing slow titration or lowering the dosage.

\section{DISCUSSION}

These case studies involved two adolescents suffering from CRPS type I resistant to conventional therapy during several years of follow-up. Both cases manifested symptoms of CRPS type I, including a neuropathic-type pain that resulted in a significant and progressive deterioration in daily functioning and overall quality of life. Dronabinol treatment in both cases resulted in dramatic improvements in physical, psychosocial and role functioning at a four-month follow-up. While no appreciable reduction in the intensity of the neuropathic pain was evident, both adolescents remarked on the change in the affective component of their pain experience in that the pain was less bothersome. While these improvements dissipated over time, the patients were more reconnected with rehabilitation and focused less on the intrusiveness of their pain in their every day lives. Furthermore, the side effects were minimal and were reduced or eliminated by slow titration or reduction of dosage.

Current literature lends support to the moderate analgesic effects of a single dose of cannabinoids in humans (8). However, little information exists regarding the therapeutic potential of cannabinoids for the treatment of chronic neuropathic pain, particularly in the pediatric patient population. A questionnaire-based study of adults with chronic pain showed that small doses of smoked cannabis improved pain, mood and sleep in some patients with chronic pain (10). Given that there was no response in our patients with regard to reduction in pain intensity, we wondered whether the mode of administration may have affected the results. While animal studies suggest that cannabinoids may be particularly potent in modulating pain behaviour in neuropathic pain models, the exact mechanism is largely unknown. A distinct cannabinoid receptor (CB 1) has been identified, and was shown to exert an inhibitory effect on presynaptic neurotransmitter release from nerve endings. Similar to the opioid system, endogenous ligands for this receptor, endocannabinoids, were identified (anandamide and $\mathrm{N}$-arachidonylglycerol) and shown to suppress wide dynamic range and nociceptive-specific neurons.

Surprisingly, there was no reported reduction in the intensity of the neuropathic pain experienced in the affected extremity, even though there was an improvement in the affective pain component characterized by improved sleep, mood, appetite, coping, cognitive and social performance, and physical functioning. Ware $(10,11)$ reported similar findings in previous case series. A similar degree and duration of improvement in these areas of functioning was not achieved by any of the multiple treatment regimens that had been tried previously on these patients. These findings suggests segregation between the actual pain perception and the accompanying symptoms, with the latter being more responsive to cannabinoid administration.

Pain is a multidimensional phenomenon, comprised of sensory, motivational and affective dimensions. Pain intensity is 
usually closely linked to pain-related unpleasantness, but not always. Another component of pain affect is the 'secondary pain affect', which includes emotional feelings directed toward the long term implications of having pain. Psychophysical and brain imaging studies demonstrate that pain sensation and pain unpleasantness are two distinct dimension of pain that are located in specific areas of the brain and are separately influenced by various psychological factors (12). It may be that dronabinol has a more selective effect on pain unpleasantness than pain sensation, and although the pain sensation intensity does not respond to the treatment, the affective pain component is significantly improved.

While cannabinoids are psychoactive drugs well-known to induce a wide range of psychological and organic side effects, in the above cases, only minor side effects were noted and the overall effect was favourable. Most striking was the effect on cognitive performance. These patients experienced a dramatic improvement in cognition and memory despite the concern that cannabinoids may impair these functions. This could possibly be explained by the prolonged sleep deprivation and mood disturbances that they both experienced as part of their

\section{REFERENCES}

1. Wilder RT. Reflex sympathetic dystrophy in children and adolescents: Differences from adults. In: Janig W, Stanton-Hicks M, eds. Reflex Sympathetic Dystrophy: A Reappraisal. Progress in Pain Research and Management. Seattle: IASP Press 6, 1996:67-77.

2. Galer BS, Henderson J, Perander J, Jensen MP. Course of symptoms and quality of life measurement in complex regional pain syndrome: A pilot study. J Pain Symptom Manage 2000;20:286-92.

3. Berde CB, Solodiuk J. Multidisciplinary programs for the management of acute and chronic pain in children. In: Schechter NL, Berde CB, Yaster M, eds. Pain in Infants, Children, and Adolescents, 2nd edn. Baltimore: Lippincott Williams \& Wilkins, 2003:471-86.

4. Lee BH, Scharff L, Sethna NF, et al. Physical therapy and cognitivebehavioral treatment for complex regional pain syndromes. J Pediatr 2002;141:135-40.

5. Walker JM, Strangman NM, Huang SM. Cannabinoids and pain. Pain Res Manage 2001;6:74-9.

6. Russo E. Cannabis for migraine treatment: The once and future prescription? An historical and scientific review. Pain 1998;76:3-8. chronic pain conditions, which improved following use of cannabinoids.

Another major concern related to chronic cannabinoid use is addiction. It is noteworthy, that after the initial phase of titration, the dosage was maintained unaltered. This response does not support the presence of an addictive process. Dronabinol has been the only therapy that has restored some degree of normality to these patients lives, albeit temporarily. This effect provided an opportunity to intensify complimentary therapeutic modalities such as physiotherapy and psychotherapy to possibly affect the long term prognosis.

In conclusion, while cannabinoids are presently indicated for chemotherapy-induced nausea and vomiting, and acquired immunodeficiency syndrome-related cachexia, we feel that in unique cases of chronic neuropathic pain syndromes resistant to conventional treatment, cannabinoids may represent a potential therapeutic option, even in pediatric patients.

ACKNOWLEDGEMENTS: The author would like to thank Dr Fiona Campbell and Dr Patricia McGrath for their generous help in preparing this case report.

7. Herzberg U, Eliav E, Bennett GJ, Kopin IJ. The analgesic effects of R (+)-WIN 55,212-2 mesylate, a high affinity cannabinoid agonist, in a rat model of neuropathic pain. Neurosci Lett 1997;221:157-60.

8. Campbell FA, Tramer MR, Carroll D, Reynolds DJM, Moore RA. Are cannabinoids an effective and safe treatment option in management of pain? A qualitative systematic review. BMJ 2001;323:13-6

9. Abrahamov A, Abrahamov A, Mechoulam R. An efficient new cannabinoids antiemetic in pediatric oncology. Life Sci 1995;56:2097-102.

10. Ware MA, Doyle CR, Woods R, Lynch ME, Clark AJ. Cannabis use for chronic non-cancer pain: Results of a prospective study. Pain 2003;102:211-6.

11. Ware MA, Gamsa A, Persson J, Fitzcharles MA. Cannabis for chronic pain: Case series and implication for clinicians. Pain Res Manage 2002;7:95-9.

12. Price DD. Psychological and neural mechanisms of the affective dimension of pain. Science 2000;288:1769-72. 


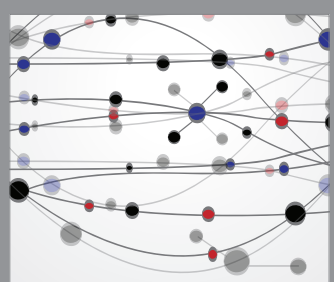

The Scientific World Journal
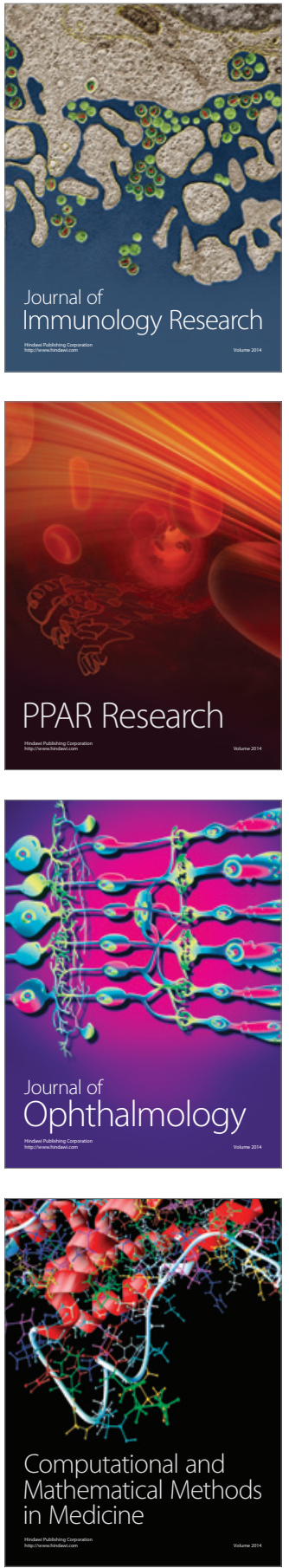

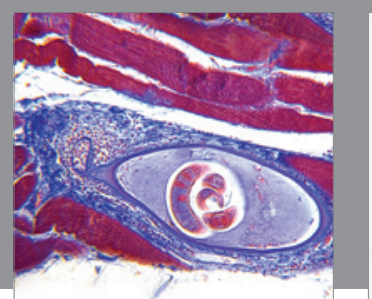

Gastroenterology Research and Practice

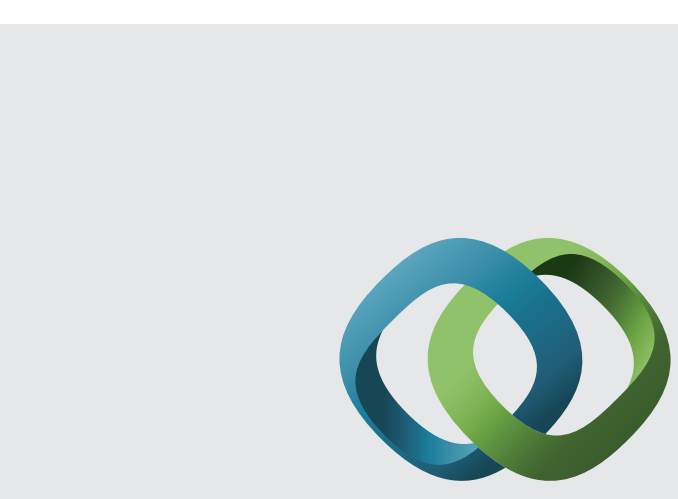

\section{Hindawi}

Submit your manuscripts at

http://www.hindawi.com
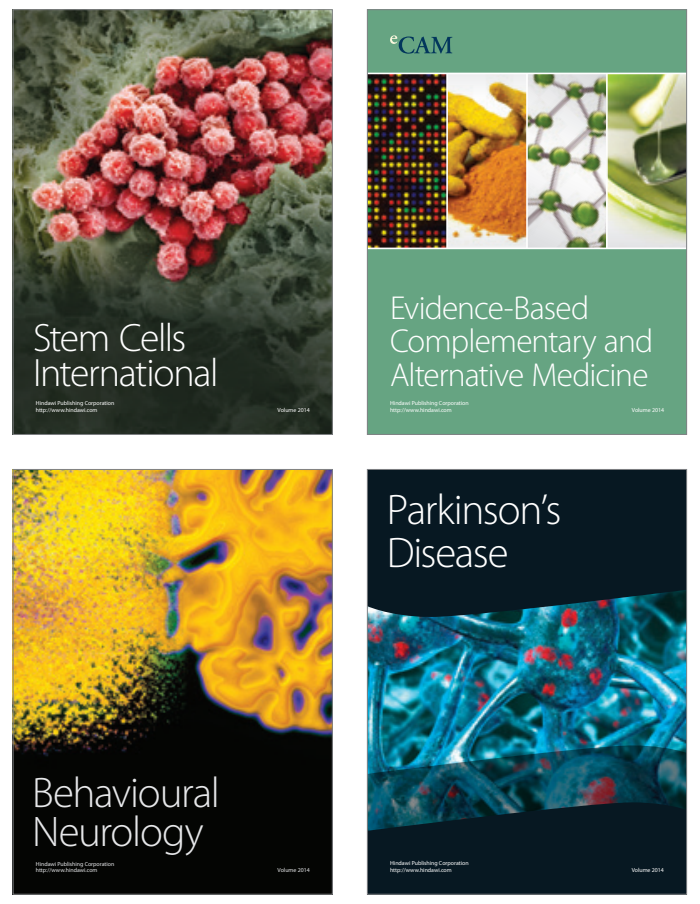
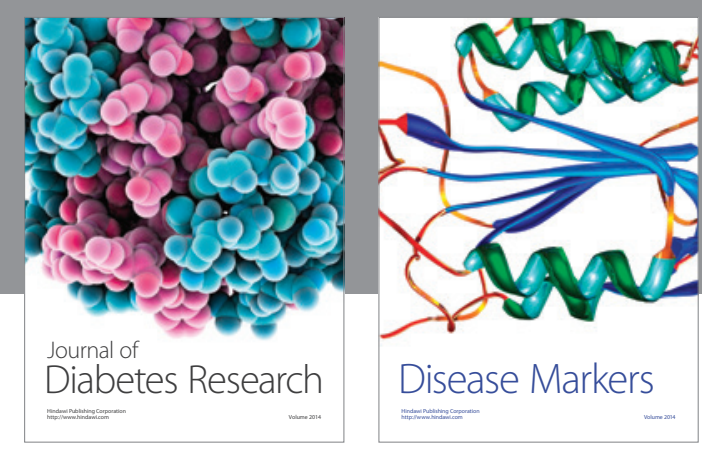

Disease Markers
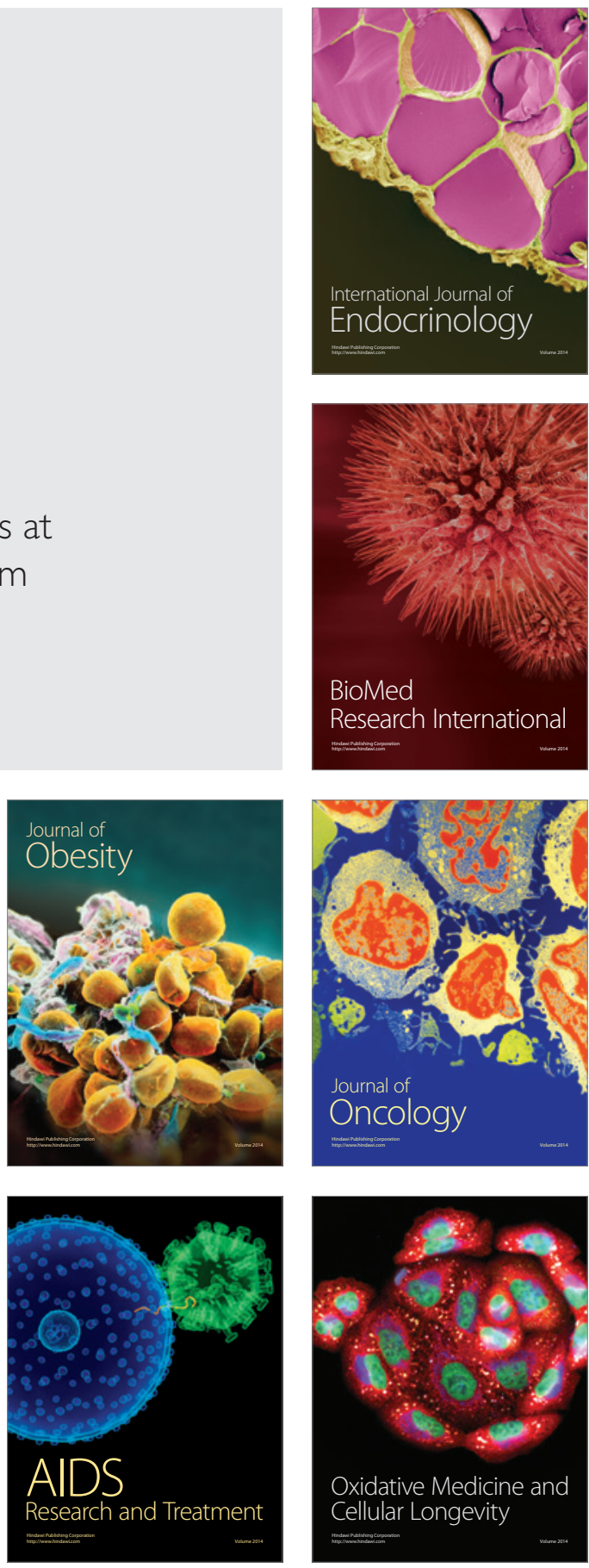